\title{
Aplikasi Pemesanan Karantina dan Pengiriman Paket Ikan PD. Masterindo Laju Abadi di Tangerang Berbasis Android
}

\author{
Nunu Kustian ${ }^{1}$, Dudi Parulian ${ }^{2}$ \\ Informatika, Universitas Indraprasta, Jakarta, Indonesia \\ e-mail: ${ }^{1} k u s t i a n n u n u @$ gmail.com, ${ }^{2}$ paruliandudi@gmail.com
}

Submitted Date: August $30^{\text {th }}, 2020$

Revised Date: September $23^{\text {rd }}, 2020$
Reviewed Date: September 22 $2^{\text {nd }}, 2020$

Accepted Date: September $30^{\text {th }}, 2020$

\begin{abstract}
The more technology develops, the more it creates a consumptive society pattern. Apart from shopping, the shipping sector has also experienced many developments. PD. Masterindo Laju Abadi provides shipping and quarantine services for fish shipments, where each fish sent must have a quarantine document in order to be sent. However, the management of shipping data and tracking of receipts is still done manually, causing several errors in data retrieval or in calculating bills. If this condition is allowed to drag on, then the hope to increase the company's productivity cannot be fulfilled and it is more difficult to achieve, therefore it is better if this service sector is supported by existing technology, so that it can make it easier for fish sellers to run their business. This research takes the theme of the business that is carried out by PD. Masterindo Laju Abadi, a shipping service company that collaborates with JNE and Caratina which only provides a few employees in the office division to handle a variety of different jobs, therefore it would be better if a job done by these few people can be handled properly and efficient.
\end{abstract}

Keywords: Delivery; quarantine; fish; Android; PD Masterindo Laju Abadi

\section{Abstrak}

Semakin berkembangnya teknologi, semakin banyak juga menimbulkan pola masyarakat yang konsumtif. Selain dalam hal belanja, bidang pengiriman juga mengalami banyaknya perkembangan. PD. Masterindo Laju Abadi menyediakan jasa pengiriman dan karantina untuk pengiriman ikan, di mana setiap ikan yang dikirim harus mempunyai dokumen karantina agar dapat dikirim. Namun dalam pengelolaan data pengiriman serta pelacakan resi masih dilakukan tanpa menggunakan database, sehinga menyebabkan beberapa kesalahan dalam pencarian data atau dalam menghitung tagihan. Kondisi seperti ini tidak bisa dibiarkan berlarut-larut, sehingga untuk meningkatkan produktivitas yang tidak dipenuhi dan sulit dicapai oleh karena itu ada baiknya jika bidang jasa ini didukung oleh teknologi yang ada, sehingga dapat memudahkan seller ikan dalam menjalankan bisnisnya. Penelitian ini mengambil tema pada bisnis yang dilaksanakan PD. Masterindo Laju Abadi sebuah perusahaan jasa pengiriman yang bekerjasama dengan JNE serta karatina yang hanya menyediakan sedikit pegawai di bagian kantor untuk menangani berbagai pekerjaan berbeda-beda, maka akan lebih baik jika suatu pekerjaan yang dilakukan oleh sedikit orang tersebut bisa ditangani dengan tepat dan efisien.

Kata Kunci: Pengiriman; karantina; Ikan; Android; PD Masterindo Laju Abadi

\section{Pendahuluan}

Perusahaan PD. Masterindo Laju Abadi adalah sebuah perusahaan yang bergerak di bidang jasa, terletak di Jl. Pinus Raya No. 239 RT 13/5 untuk kantor pusat dan Jl. Maulana hasanudin no.98 Cipondoh, Tangerang, kota Tangerang Banten, 15148. Perusahaan ini terbentuk karena adanya kebutuhan para penjual ikan dalam jasa pengiriman. Dengan adanya peluang tersebut PD. Masterindo Laju Abadi memulai jasa karantina dan pengiriman ikan di Jakarta dan sekitarnya dengan menggunakan sistem penjemputan paket.

PD. Materindo Abadi merupakan perusahaan yang menyediakan jasa karantina ikan dan pengiriman paket ikan dengan memiliki 5 karyawan, perusahaan ini menawarkan solusi 
jemput bola melalui para kurir perusahaan untuk menjemput paket ikan yang ingin dikirimkan keluar kota atau pulau oleh para penjual ikan.

Perusahaan ini berdiri pada tahun 2016, dengan kegiatan awal menaungi agen logistik TIKI dan JNE. Awal mulanya paket ikan yang sudah dijemput dan dikarantina, langsung dikirimkan melalui agen TIKI dan JNE sesuai permintaan pengirim (penjual ikan). Area penjemputan paket pada awal 2016 meliputi Tanggerang, Jakarta Barat, dan Depok. Kemudian pada Maret 2017, perusahaan ini mulai memperluas cakupan area penjemputan menjadi mencakup wilayah JaDeTa (Seluruh Jakarta, Depok dan Tanggerang). Pada awal tahun 2018, cakupan wilayahnya sudah mencakup area JaBoDeTaBek (Seluruh Jakarta, Bogor, Depok, Tanggerang, dan Bekasi). Proses penjemputan paket dilakukan pada Senin-Jumat, dikarenakan permintaan penjemputan paket ikan dari berbagai wilayah JaBoDeTaBek, proses

Penjemputan sudah mulai diberlakukan penjadwalan penjemputan paket di setiap area, hingga pada pertengahan tahun 2018 terjadi kendala yang tidak diduga dari perusahaan partner logistik yaitu TIKI dan JNE yang secara resmi menerbitkan surat larangan pengiriman hewan dalam bentuk apapun melalui jalur udara. Berawal dari masalah tersebut, PD. Masterindo Laju Abadi mulai melakukan kerjasama dengan perusahaan kargo untuk menopang kebutuhan logistik pengiriman paket ikan, yaitu dengan Garuda Indonesia Air Cargo Service.

Hingga saat ini PD. Masterindo Laju Abadi sudah mendukung pengiriman paket melalui jalur udara dari Bandara Soekarno Hatta ke beberapa wilayah di Indonesia. Setelah paket sampai di bandara tujuan, kemudian diteruskan melalui jalur darat oleh transhipper.Semakin berkembangnya teknologi, semakin banyak juga menimbulkan pola masyarakat yang konsumtif. Selain dalam hal belanja, bidang pengiriman juga mengalami banyaknya perkembangan. PD. Masterindo Laju Abadi menyediakan jasa pengiriman dan karantina untuk pengiriman ikan, dimana setiap ikan yang dikirim harus mempunyai dokumen karantina agar dapat dikirim. Namun dalam pengelolaan data pengiriman serta pelacakan resi masih dilakukan secara manual, sehinga menyebabkan beberapa kesalahan dalam pencarian data atau dalam menghitung tagihan. Kondisi seperti ini tidak bisa dibiarkan berlarut-larut, sehingga untuk meningkatkan produktivitas yang tidak dipenuhi dan sulit dicapai oleh karena itu ada baiknya jika bidang jasa ini didukung oleh teknologi yang ada, sehingga dapat memudahkan seller ikan dalam menjalankan bisnisnya.

Materi pada penelitian ini mengambil tema pada bisnis yang dilaksanakan PD. Masterindo Laju Abadi. Perusahaan ini begerak jasa pengiriman yang bekerja sama dengan JNE serta karatina. Penelitian ini menghasilkan sistem secara daring menggunakan teknologi berbasis android dengan menggunakan jaringan internet. Sistem ini mengganti proses bisnis yang dilakukan oleh PD. Masterindo Laju Abadi yang sebelumnya dilakukan tanpa menggunakan database. Aplikasi yang dirancang dapat membantu proses bisnis menjadi lebih efektif dan efisien.

\section{Metodologi}

Proses pengumpulan data adalah kegiatan paling strategis dalan penelitian, karena mendapatkan data merupakan tujuan utama dari penelitian, Sugiyono (2013:2). Penelitian kaulitatif adalah metode yang digunakan yang bersifat deskriptif dan cenderung menggunakan analisis. Adapun teknik-teknik pengumpulan data yang dilakukan dalam kuliah praktek adalah:

a. Observasi

Obervasi atau pengamatan yang dilakukan di PD Masterindo Laju Abadi berkaitan dengan pengiriman dan karantina ikan pada sistem yang berjalan.

b. Wawancara

Kegiatan wawancara dilaksanakan dengan pimpinan di PD Masterindo Laju Abadi.

c. Kepustakaan

Penelitian kepustakaan dilakukan dengan menggunakan kepustakaan, yang terdiri dari buku, catatan maupun hasil penelitian sebelumnya.

\subsection{Metode Pengembangan Sistem}

Pengembangan sistem dalam penelitian ini menggunakan model waterfall. Metode ini menggunakan pendekatan secara sistematis dan juga berurutan. Proses pengembangannya dimulai dengan mendapatkan spesifikasi kebutuhan, tahapan perencanaan, permodelan, konstruksi, kemudian menyerahakan sistem ke pelanggan/pengguna. Proses ini diakhiri dengan menghasilan perangkat lunak lengkap yang siap digunakan (Pressman, 2012). 


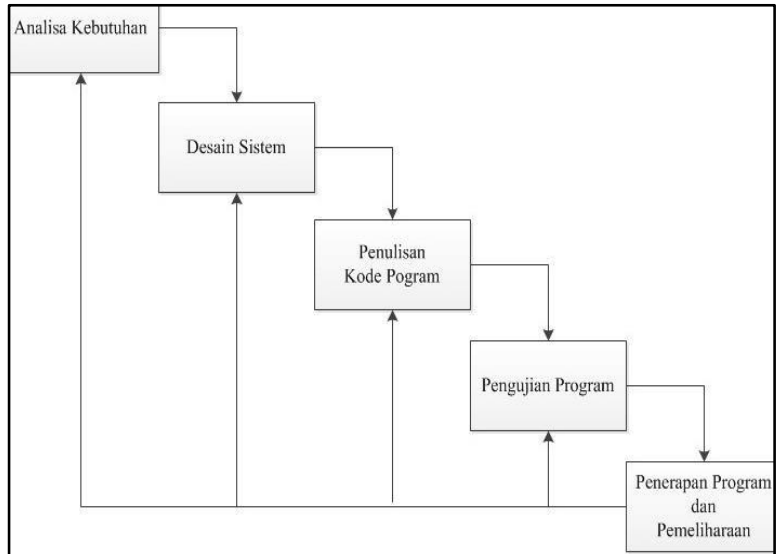

Gambar 1. Model Pengembangan Sistem Waterfall

\subsection{Perancangan Sistem}

Peraturan Pemerintah Republik Indonesia No. 15 Tahun 2002, "Karantina ikan merupakan tindakan pencegahan masuk dan tersebarnya hama dan penyakit pada ikan. Karantina dari luar negeri dan dari suatu Area ke Area lain di dalam negeri, atau keluarnya dari dalam wilayah Negara Republik Indonesia”. atau organisme pengganggu dari suatu area atau keluar dari wilayah tersebut. Maka dari itu penjual ikan yang ingin mengirim ikannya membutuhkan dokumen karantina yang merupakan formulir resmi yang ditetapkan oleh menteri dalam rangka tertib administrasi pelaksana tindakan karantina.

Pemesanan adalah suatu proses yang dilakukan oleh seseorang untuk memesan sesuatu. Jadi pemesanan karantina ikan adalah suatu proses yang dilakukan seseorang untuk mendapatkan dokumen karantina ikan.

\subsubsection{Pengiriman Paket Ikan}

Peranan logistik sangatlah penting dan tidak terpisahkan dari aktivitas suatu perusahaan, baik perusahaan yang bergerak dibidang logistik maupun tidak berhubungan dengan logistik (Yohanes, 2016). Pengiriman adalah kegiatan pemasaran untuk memudahkan dalam penyampaikan produk dari produsen kepada konsumen. Menangani masalah pengiriman tanpa dibantu oleh beberapa penyedia jasa pengiriman itu sendiri. Jadi, kegiatan tersebut memudahkan penjual ikan untuk mendistribusikan ikannya. Pada PD. Masterindo Laju Abadi menggunakan jasa pengiriman Garuda Indonesia Cargo. Harga Garuda Cargo sangat terjangkau dan ada jaminan paket tiba tepat waktu. Paket pengiriman menggunakan Garuda Cargo mendapat jaminan dan prioritas dalam proses pengiriman 1-2 hari saja.

\subsubsection{Proses Bisnis}

Proses bisnis ini menjelaskan bagaimana sistem bekerja dari Aplikasi Pemesanan Karantina dan Pengiriman Paket Ikan PD. Masterindo Laju Abadi yaitu:

1. Pelanggan melakukan pendaftaran pembuatan akun.

2. Pelanggan melakukan login sebagai Pengguna.

3. Pelanggan melakukan inputan pemesanan karantina sesuai tanggal yang dipilih.

4. Kurir menerima jadwal pengambilan dari pelanggan. Setelah itu kurir menjemput paket dan membawa kembali ke kantor untuk diproses karantina dan pengiriman, kemudian kurir mengubah status dalam sistem bahwa paket sudah berhasil diangkut.

5. Setelah menerima paket yang diangkut, Admin menginput biaya karantina yang diterima langsung notifikasinya oleh pelanggan.

6. Paket ikan yang sudah dikarantina, diperbaharui statusnya menjadi dikirim dan admin menginput biaya pengiriman dan nomer resi yang sudah ada.

7. Admin membuat laporan hasil pengiriman dan karantina.

8. Pimpinan menerima laporan pengangukan, laporan hasil pengiriman, laporan karantina.

\subsubsection{Peraturan Bisnis}

Dalam aturan bisnis di dalamnya menjelaskan tentang kebijakan-kebijakan pada sistem yang dibahas antara lain:

1. Apabila pengguna login sebagai customer maka hak akses terbatas.

2. Apabila pengguna login sebagai kurir maka hak akses terbatas.

3. Apabila pengguna login sebagai admin hak akses penuh kepada Aplikasi

4. Pemesanan Karantina dan Pengiriman Paket Ikan PD. Masterindo Laju Abadi. 


\subsubsection{Dekomposisi Fungsi}

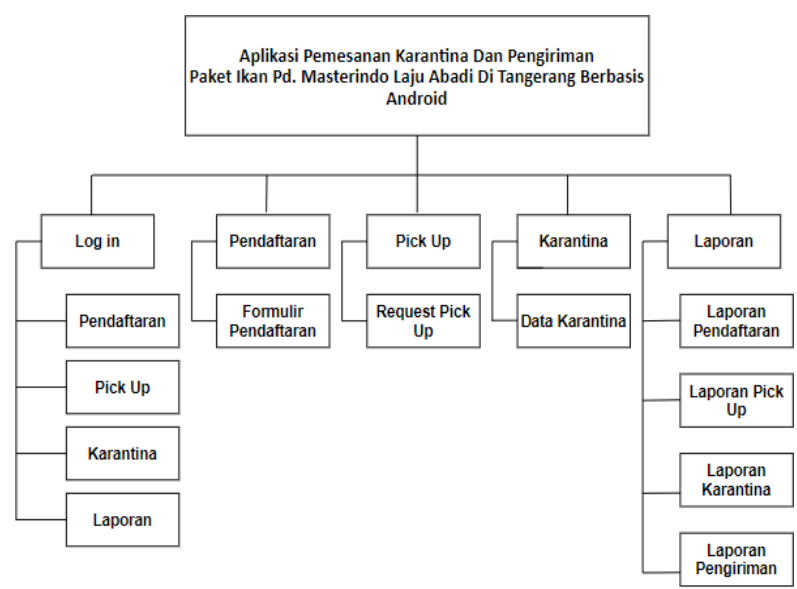

Gambar 2 Dekomposisi Fungsi Sistem

Dalam dekomposisi fungsi menggambarkan fungsi yang pada sistem aplikasi Inventaris PD. Masterindo Laju Abadi sistem yang bekerja dapat diakses oleh Admin untuk mengawasi semua aktifitas barang masuk dan barang keluar yang dibelanjakan ataupun yang telah terpakai.

\subsubsection{Diagram Aliran Data}

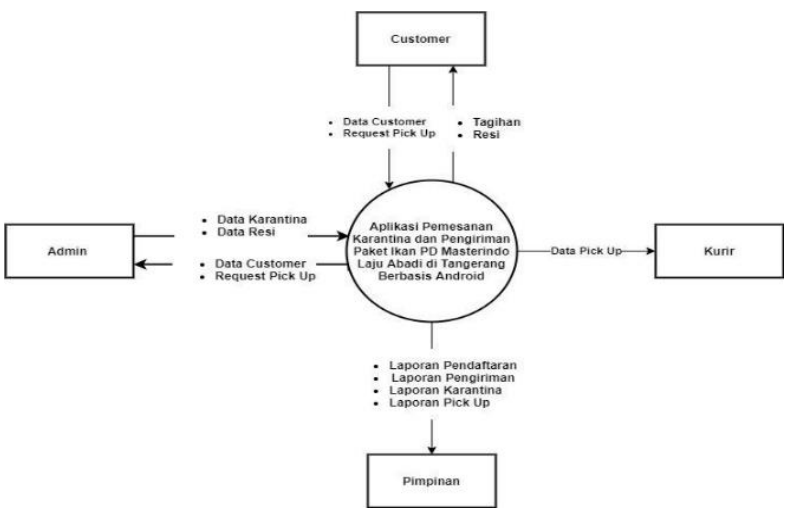

Gambar 3 Diagram Konteks PD. Masterindo Laju Abadi

\subsubsection{Diagram Relasi Antar Objek}

Dalam diagram ini dijelaskan rancangan data secara logika menggunakan symbol-simbol sesuai aturan baku. Diagram ini menjelaskan relasi antar objek yang ada pada rancangan sistem yang dikembangkan untuk system bisnis pada PD. Masterindo Laju Abadi.

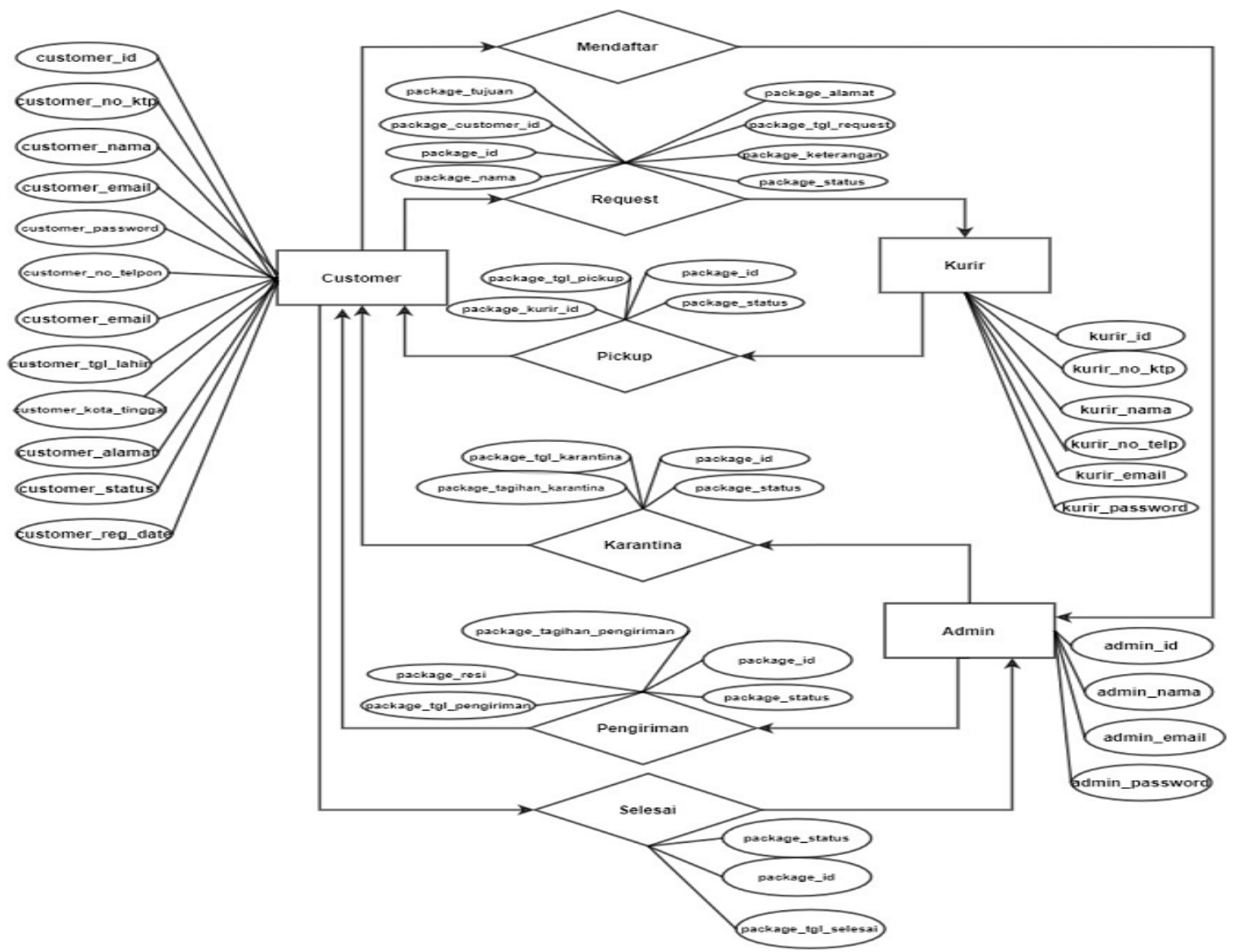

Gambar 4. Entity Relationship Diagram 


\section{Hasil dan Pembahasan}

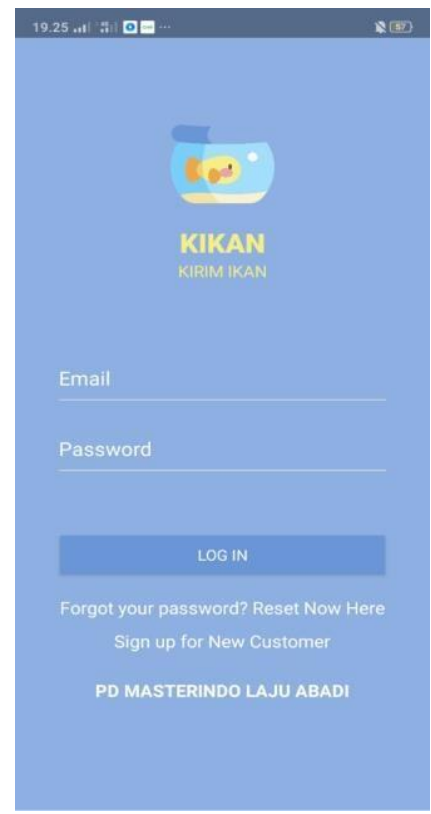

Gambar 5. Menu Log in

Gambar 5 menampilkan tampilan untuk pengguna masuk ke sistem. Tampilan halamana ini mengharuskan pengguna memasukan user dan password sesuai dengan akun milik pengguna.

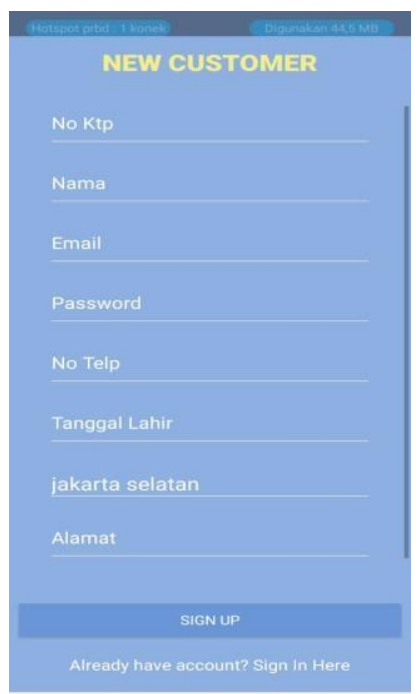

Gambar 6. Tampilan New Customer

Gambar 6 menampilkan halaman registrasi bagi pengguna baru. Pengguna baru diharuskan memasukan data sesuai yang diminta oleh sistem yang ditunjukan pada tampilan form.

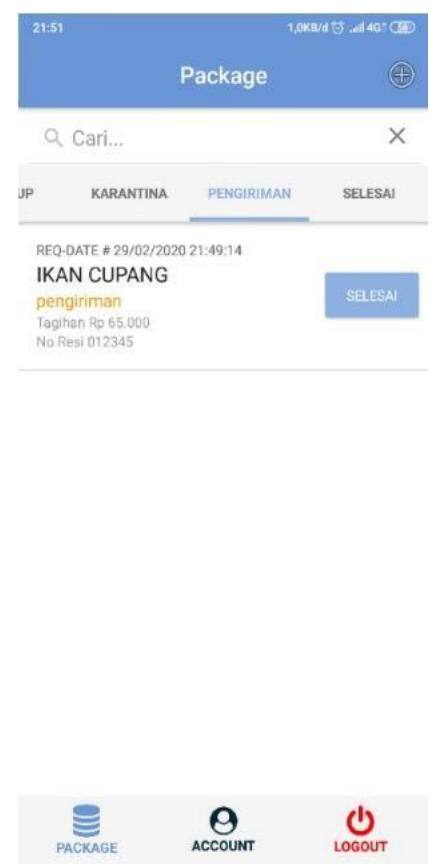

Gambar 7. Form Request Pickup

Gambar 7 menjelaskan data pengiriman oleh pengguna. Data pengiriman ini akan diteruskan kepada kurir untuk diambil dan dikirim sesuai permintaan pengguna.

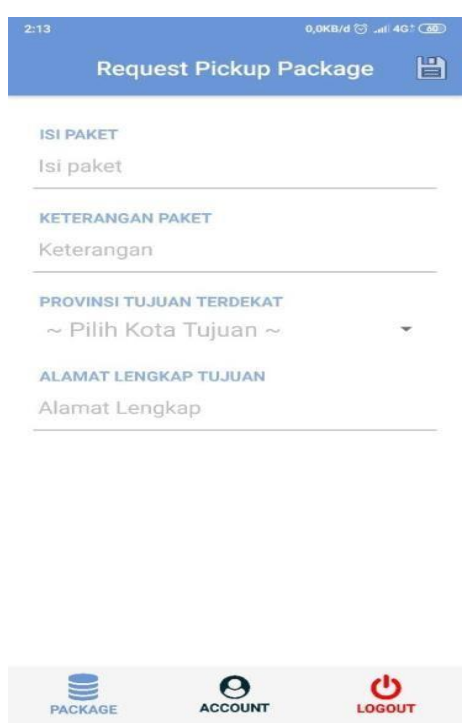

Gambar 8. Tampilan Status Pengiriman

Pada gambar 8 dijelaskan bahwa paket pengiriman dapat ditelusuri sesua permintaan pengguna. Paket pengiriman ini sesuai dengan isian oleh pengguna agar kurir mengirim seuai dengan alaman yang benar. 


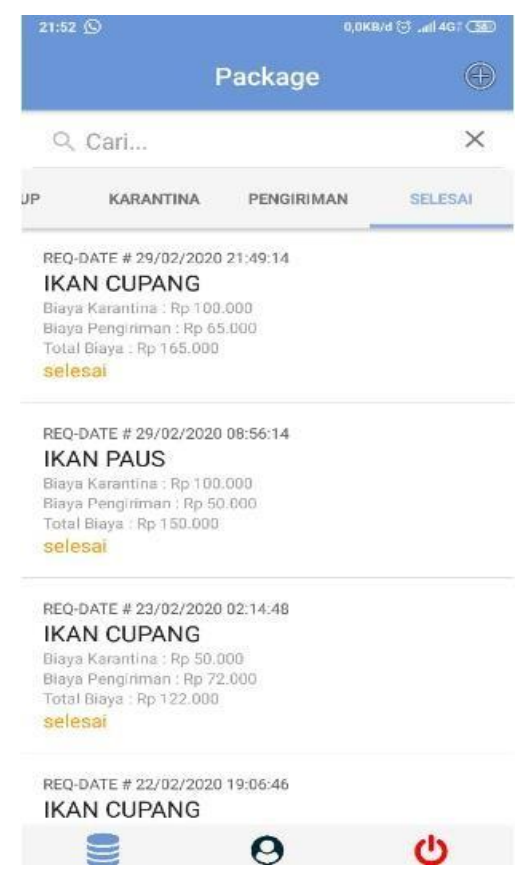

Gambar 9. Tampilan Pesanan Selesai

Gambar 9 menjelaskan daftar paket yang sudah dipesan oleh pengguna. Daftar peket ini akan mempunyai status selesai dikirim jika sudah diambil dan diantarkan oleh kurir.

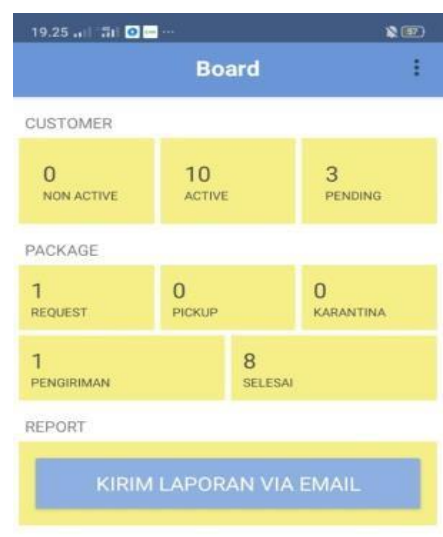

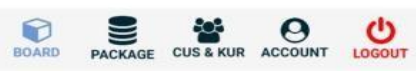

Gambar 10 Tampilan Menu Admin

Pada gambar 10 menjelaskan menu yang dapat diakses oleh pengguna sistem dengan level administrator. Pengguna admin dapat mengakses semua menu yang terdapat pada sistem.

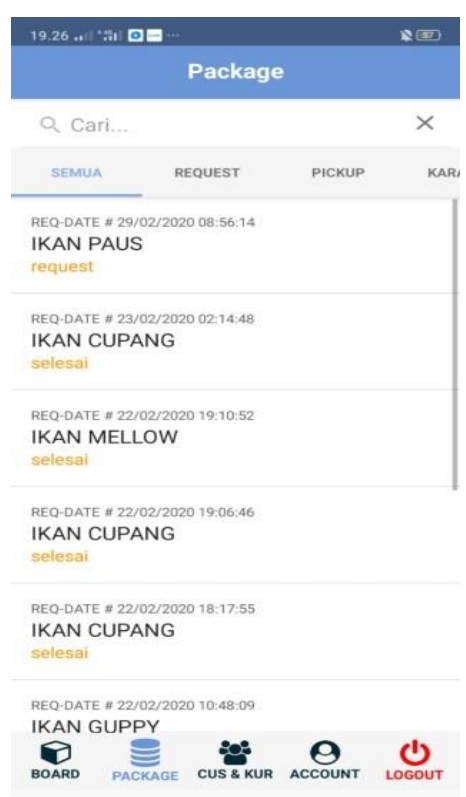

Gambar 11 Tampilan Status Pemesanan Admin

Gambar 11 menjelaskan status dari semua pemesanan yang sudah dilakukan oleh pengguna pelanggan. Semua daftar pemesanan pengiriman oleh pelanggan dapat diawasi oleh admin.

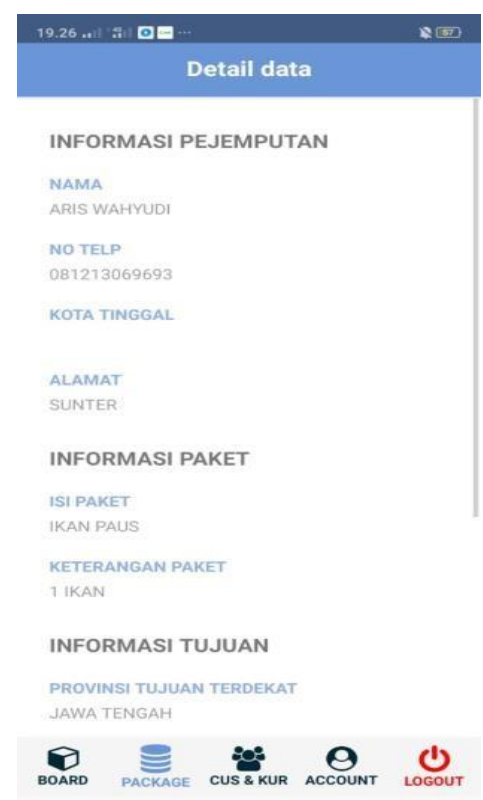

Gambar 12 Tampilan Detail Data Pemesanan

Gambar 12 menjelaskan detail informasi tujuan pengiriman paket semua pelanggan. Semua pelanggan dapat ditampilkan informasi secara detail. 


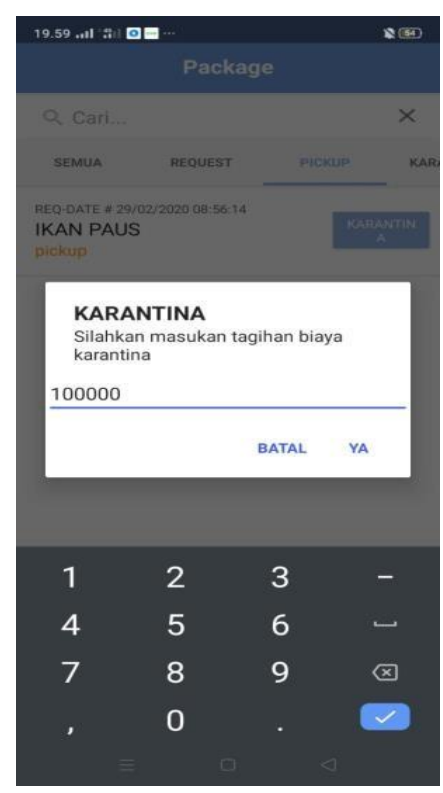

Gambar 13 Tagihan Karantina Admin

Gambar 13 dijelaskan biaya karantina dari paket yang disimpan di dalam gudang. Biaya karantina ini disesuaikan dengan biaya karantina sesuai ketentuan yang berlaku.

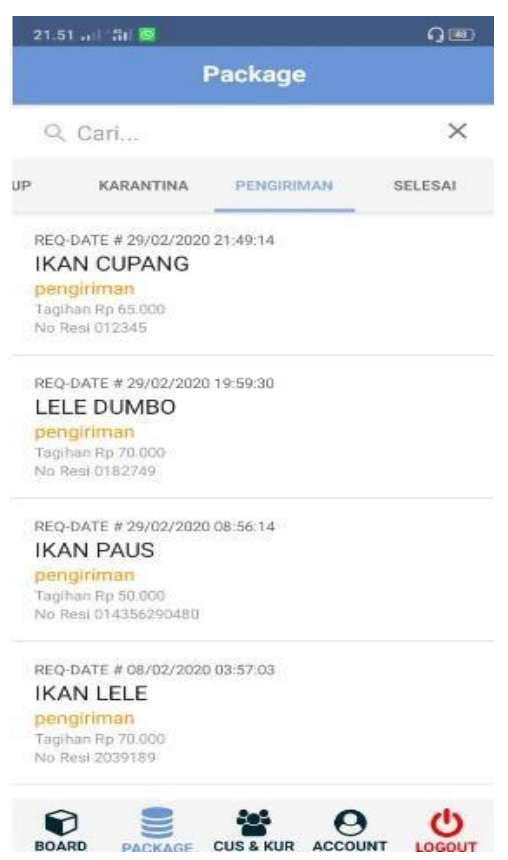

Gambar 14. Tampilan Daftar Pengiriman

Gambar 14 menjelaskan data pengiriman paket ikan yang dikarantina milik pelanggan. Daftar paket ini berisi penjelasan isi dari ikan yang dikarantina.

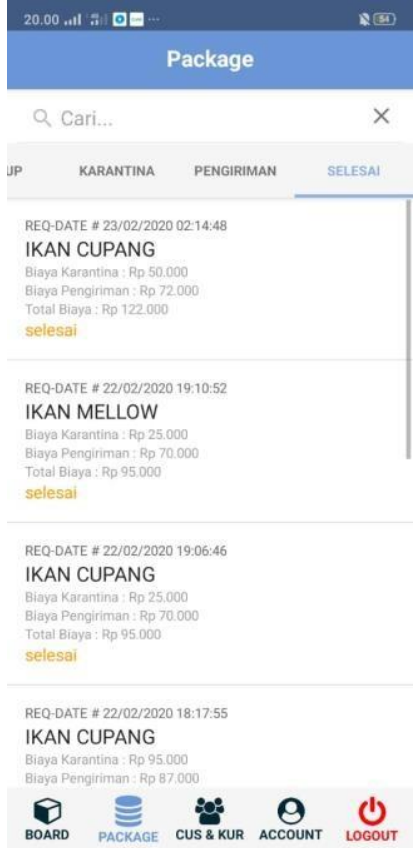

Gambar 15 Tampilan Pemesanan Selesai Admin

Gambar 15 menjelaskan jika pemesanan sudah selesai. Pemesanan dikatakan sudah selesai jika ikan yang dikarantina sudah dikirim oleh kurir kepada pemilik atau pelanggan.

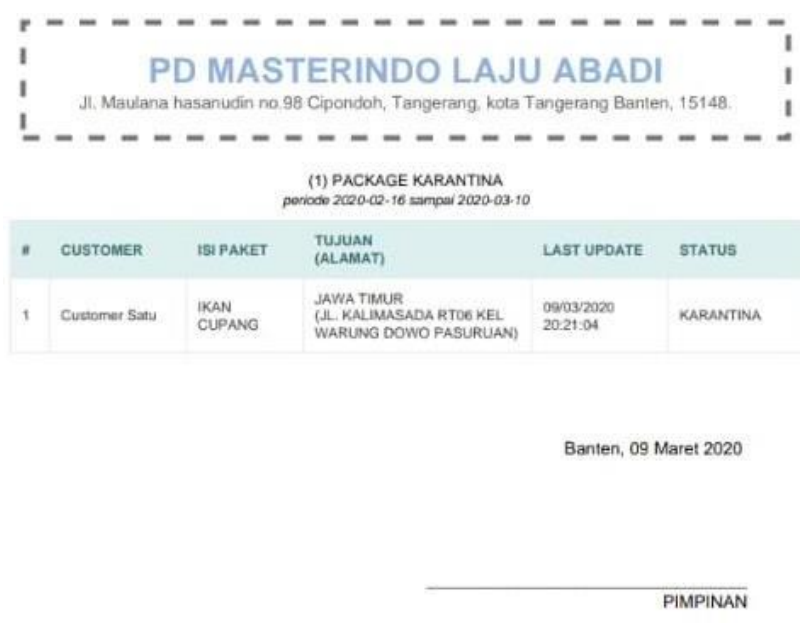

Gambar 16 Tampilan Laporan Karantina

Gambar 16 menjelaksan data laporan secara keseluruhan data karantina ikan. Laporan karantina ini dapat disesuaikan dengan kebutuhan baik dibuat secara periode waktu atau secara pelanggan atau berdasarkan jenis ikan yang dikarantina. 

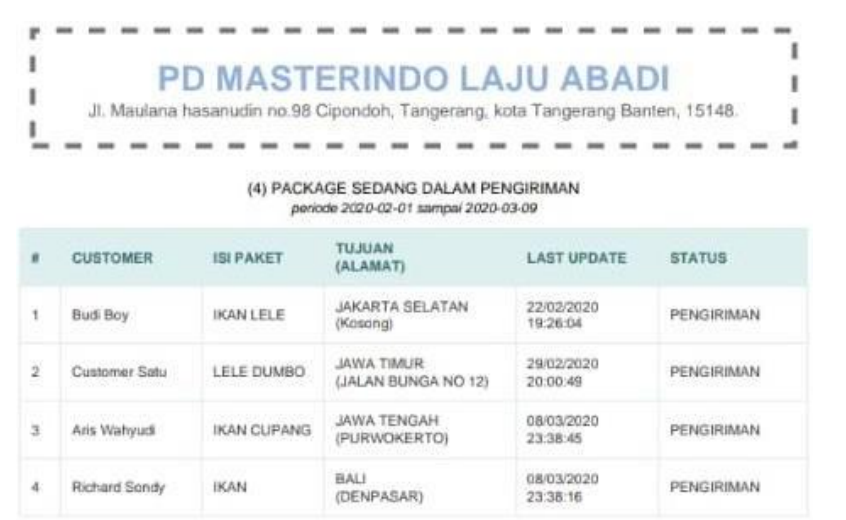

Banten, 09 Maret 2020

PIMPINAN

Gambar 17 Tampilan Laporan Pengiriman

Gambar 17 menjelaksan data laporan secara keseluruhan data pengiriman. Laporan pengiriman ini dapat disesuaikan dengan kebutuhan baik dibuat secara periode waktu atau secara pelanggan atau berdasarkan jenis ikan yang dikirim.

\section{Simpulan}

Berdasarkan penelitian, hasil rancangan sistem, dan pembahasan yang telah kami lakukan, maka kami membuat simpulan yang berhubungan dengan pembahasan yaitu:

1. Pembangunan Aplikasi Pemesanan Karantina dan Pengiriman Paket Ikan PD Masterindo Laju Abadi di Tangerang Berbasis Android ini dimaksudkan untuk dapat menangani pekerjaan staff admin dan pelanggan dalam pengolahan data, pengiriman dan karantina secara cepat, akurat, dan efisien.

2. Aplikasi Pemesanan Karantina dan Pengiriman Paket Ikan PD Masterindo Laju Abadi di Tangerang Berbasis Android ini membawa dampak yang baik terhadap PD Masterindo Laju Abadi, karena efektifitas dan efisiensi dapat tercapai dalam hal pengiriman dan karantina yang terkomputerisasi dan terintegrasi secara baik.

3. Aplikasi Pemesanan Karantina dan Pengiriman Paket Ikan PD Masterindo Laju Abadi di Tangerang Berbasis Android yang telah dibuat dapat meningkatkan pengawasan terhadap pelaksanaan kegiatan yang lebih mudah karena adanya laporan atau informasi kegiatan yang tepat waktu dan dapat disajikan setiap saat ketika dibutuhkan.

\section{Saran}

Berdasarkan kesimpulan di atas, maka penelitian ini dapat memberikan saran yang dapat menjadi bahan masukan dan sebagai bahan pertimbangan bagi PD Masterindo Laju Abadi sebagai berikut:

1. Aplikasi Pemesanan Karantina dan Pengiriman Paket Ikan yang dibuat masih harus diadakan evaluasi secara berkala agar aplikasi dapat dikembangkan dan dapat menjadi lebih baik untuk digunakan dengan penelitian atau analisa yang lebih spesifik.

2. Dalam hal tampilan Aplikasi Pemesanan Karantina dan Pengiriman Paket Ikan ini masih sangat sederhana dan masih membutuhkan penambahan desain atau fitur yang sesuai dengan kebutuhan dalam kegiatan di perusahaan

3. Melakukan pemeliharaan data dengan backup data secara berkala untuk mengantisipasi segala kemungkinan yang dapat terjadi terhadap

\section{Referensi}

Hutahaean, J. (2014). Konsep Sistem Informasi. Yogyakarta: CV. Budi Utama.

Ichwan Muhamad, M. G. (2013). Pembangungan Prototipe Sistem Pengendalian Peralatan Listrik Pada Platform Android. Bandung: Institut Teknologi Nasional .

Kristanto, A. (2018). Perancangan Sistem Informasi dan Aplikasinya. Yogyakarta: Gava Medika.

Nugraha Yohanes, M. d. (2016). Biaya Logistik Dan Kelancaran Pengiriman Barang Pada Gerai Buku. Jurnal Institut Transportasi dan Logistik Trisakti, Vol 3, No 2.

Perikanan, K. K. (2020, 02 15). Peraturan Pemerintah Republik Indonesia Nomor 15 Tahun 2002. Retrieved from Kementrian Kelautan dan Perikanan: http://kkji.kp3k.kkp.go.id/

Rachmat, A. d. (2016). Konsep \& Implementasi Pemrograman GUI. Yogyakarta: ANDI.

Rawung, F. (2017). Aplikasi Sms Dengan Php Dan Mysql. Yogyakarta: Grava Media.

Roger S. Pressman, P. (2012). Rekayasa Perangkat Lunak (Pendekatan Praktisi).7th Ed. Yogyakarta: ANDI.

Sugiyono. (2013). Metode Penelitian Kuantitatif, Kualitatif, dan R\&D. Cetakan Ke 19. Bandung: Alfabeta. 